\title{
PEMANFAATAN DATA SATELIT TROPICAL RAINFALL MEASURING MISSION 3A25 DAN 3B43 SEBAGAI INPUT MODEL ITU-R UNTUK MENGESTIMASI INTENSITAS CURAH HUJAN DI INDONESIA
}

\author{
Dea Kurnia Harysandi, Marzuki Marzuki*
}

Jurusan Fisika, FMIPA, Universitas Andalas, Limau Manis, Padang, 25163

*Korespondensi ke: marzuki@sci.unand.ac.id

( Diterima:08 Juli 2019; Direvisi: 25 Juli 2019; Diterbitkan: 01 September 2019 )

\begin{abstract}
ABSTRAK
Model yang dikeluarkan oleh International Telecommunication Union-Radiocommunication Sector (ITU-R) digunakan secara luas untuk menentukan intensitas curah hujan dalam pemodelan penjalaran gelombang elektromagnetik dalam medium hujan. Parameter yang digunakan untuk menentukan intensitas curah hujan adalah curah hujan rata-rata tahunan (Mt) dan probabilitas hujan (P0). Input data dari model ITU-R berasal dari data 40-year ECMWF re-analysis (ERA-40) dengan resolusi spasial dan temporal yang rendah. Penelitian ini menguji penggunaan data satelit Tropical Rainfall Measuring Mission (TRMM) 3A25 dan 3B43 yang memiliki resolusi spasial yang lebih baik sebagai input data ITU-R (ITU-R P.837-6). Data TRMM yang digunakan adalah data dari tahun 1998 sampai 2014. Hasil estimasi dibandingkan dengan model ITU-R standar dan kemudian divalidasi dengan data rain gauge di Kototabang dan data DBSG3 untuk Bandung. Hasil penelitian menunjukkan bahwa penggunaan data TRMM 3A25 dan 3B43 sebagai input model ITU-R P.837-6 cukup akurat untuk mengestimasi curah hujan di Indonesia. Nilai root mean square error (RMSE) dan persentase error yang didapatkan dari data TRMM dan model ITU-R tidak jauh berbeda ketika dibandingkan dengan data rain gauge dan DBSG3. Untuk keseluruhan data di Kototabang, nilai RMSE dari TRMM dan ITU-R berturut-turut adalah 21,97 dan 16,70 mm/h dengan persentase error 16,28\% dan 9,63\%. Untuk Bandung, nilai RMSE ketika dibandingkan dengan data DBSG3 adalah $8,72 \mathrm{~mm} / \mathrm{h}$ (TRMM) dan 1,72 $\mathrm{mm} / \mathrm{h}$ (ITU-R) dengan persentase error $16,18 \%$ (TRMM) dan 11,13\% (ITU-R). Dengan demikian, ITU-R dengan input ERA-40 lebih akurat dari ITU-R dengan input TRMM 3A25 dan 3B43 untuk mengestimasi intensitas curah hujan menitan di Indonesia.

Kata kunci: Intensitas curah hujan, TRMM, ITU-R P.837-6, Indonesia
\end{abstract}




\begin{abstract}
International Telecommunication Union-Radiocommunication Sector (ITU-R) model is widely used to estimate one-minute rainfall rate in electromagnetic wave propagation model in rain medium. Estimation is based on the annual mean rainfall $\left(M_{t}\right)$ and the probability of rain $\left(P_{0}\right)$. The input of ITU-R model is derived from 40-year ECMWF re-analysis (ERA-40) with low spatial and temporal resolutions. This work replaced the input of ITU-R model (ITU-R P837-6) with the Tropical Rainfall Measuring Mission (TRMM) $3 A 25$ and $3 B 43$ data with better spatial and temporal resolutions. We used the data from 1998 to 2014. The results were validated with rain gauge data at Kototabang and DBSG3 data at Bandung. Although the TRMM data is accurate enough to be used as the input of ITU-R model to estimate one-minute rainfall in Indonesia, the accuracy of ITU-R model with the input of ERA-40 is better. The values of root mean square error (RMSE) and error percentage of TRMM are not much different from those of ITU-R model when the results were validated by rain gauge and DBSG3 data. For Kototabang, the RMSE of TRMM and ITU-R are $21.97 \mathrm{~mm} / \mathrm{h}$ and $16.70 \mathrm{~mm} / \mathrm{h}$, respectively, and the error percentages are $16.28 \%$ and $9.63 \%$, correspondingly. For Bandung, the RMSEs which are calculated using the DBSG3 data are $8.72 \% \mathrm{~mm} / \mathrm{h}($ TRMM) and $1,72 \mathrm{~mm} / \mathrm{h}($ ITU-R) with error percentage being $16,18 \%$ (TRMM) and $11,13 \%(I T U-R)$.

Keywords: rainfall rate, TRMM, ITU-R P837-6, Indonesia
\end{abstract}

\title{
1. PENDAHULUAN
}

Hujan menjadi penyebab utama terjadinya atenuasi perambatan gelombang elektromagnetik pada frekuensi di atas $10 \mathrm{GHz}$ (Azlan dkk., 2013). Frekuensi di atas $10 \mathrm{GHz}$ rentan terhadap redaman yang disebabkan oleh partikel-partikel di atmosfer yang akan menurunkan kualitas layanan telekomunikasi. Atenuasi menyebabkan penurunan intensitas radiasi gelombang elektromagnetik karena terjadi penyerapan dan hamburan oleh butiran hujan (Oguchi dkk., 1983). Intensitas curah hujan sangat berpengaruh terhadap atenuasi. Semakin tinggi intensitas curah hujan, maka semakin besar atenuasi yang terjadi. Untuk wilayah tropis seperti Indonesia, atenuasi yang terjadi cukup besar karena kawasan ini memiliki tingkat curah hujan yang tinggi (Maagt dkk., 1993). Oleh karena itu, estimasi intensitas curah hujan yang akurat diperlukan untuk memprediksi atenuasi dalam perancangan sistem telekomunikasi di Indonesia.

International Telecommunication Union-Radiocommunication Sector (ITU-R) memiliki metode yang umum digunakan untuk memprediksi statistik curah hujan yang diperlukan untuk mengestimasi atenuasi. ITU-R merekomendasikan penggunaan model matematis Complementary Cumulative Distribution Function (CCDF) untuk mengintegrasikan data hasil pengukuran ke bentuk integrasi waktu satu menit (Capsoni dan Luini, 2008). Model ITU-R mengasumsikan intensitas curah hujan stasioner sepanjang tahunnya sehingga kurang akurat pada daerah tropis karena hujannya lebih bervariasi. Perkiraan statistik curah hujan yang lebih akurat menggunakan model ITU-R kemungkinan dapat diperoleh dengan mengganti data input dari model ITU-R itu sendiri.

Model ITU-R menggunakan input dari data 40-year ECMWF re-analysis (ERA40) yang dikembangkan oleh European Centre for Medium-range Weather Forecast (ECMWF). Rendahnya resolusi spasial dan temporal dari database ERA40 diduga menjadi salah satu kelemahan model ITU-R. Resolusi spasial data ERA40 adalah $1,125^{\circ} \times 1,125^{\circ}$ dan resolusi temporalnya adalah 6 jam. Penelitian ini dilakukan dengan mengganti input dari model ITU-R dengan data satelit Tropical Rainfall Measuring Mission (TRMM) yang memiliki resolusi spasial dan temporal lebih baik dari ERA40. Data satelit TRMM yang digunakan adalah 3A25 dan 3B43. 
Azlan dkk. (2013) telah melakukan penelitian dengan memanfaatkan data TRMM 3A25 dan 3B43 sebagai pengganti data ERA40 untuk wilayah Malaysia. Hasil penelitiannya menunjukkan bahwa penggunaan data TRMM 3A25 dan 3B43 pada model ITU-R menghasilkan estimasi yang lebih akurat dari penggunaan data ERA40. Meylani (2017) menggunakan data TRMM 3B42 dengan resolusi spasial $0,25^{\circ} \times 0,25^{\circ}$ dan resolusi temporal $3 \mathrm{jam}$, dan data TRMM 3B43. Intensitas curah hujan yang didapatkan mendekati hasil yang didapatkan oleh rain gauge tetapi tidak pada semua intensitas. Nilai intensitas curah hujan mendekati data rain gauge hanya pada percentage time $(p)<0,01 \%$ (hujan dengan intensitas ringan dan sedang). Oktaviani dan Marzuki (2019) dan Marzuki dkk. (2018) menggunakan data GSMaP dengan resolusi spasial $0,1^{\circ} \times 0,1^{\circ}$ dan resolusi temporal 1 jam sebagai pengganti input standar ITU-R. Kedua penelitian ini juga mendapatkan intensitas curah hujan yang mendekati rain gauge pada sebagian intensitas saja $(p<0.01 \%)$ sebagaimana yang diperoleh oleh Meylani (2017). Berdasarkan hal tersebut, penelitian ini tertarik untuk menguji penggunaan data TRMM 3A25 dan 3B43 sebagai input model ITU-R di Indonesia.

\section{METODE PENELITIAN}

Data utama yang digunakan adalah data satelit TRMM 3A25 dan 3B43. TRMM 3A25 berasal dari sensor Precipication Radar (PR) dengan resolusi spasial $0,5^{\circ} \times 0,5^{\circ}$. TRMM 3B43 adalah data hujan dari TRMM dan gabungan dari beberapa sensor satelit meteorologi dengan resolusi $0,25^{\circ} \times 0,25^{\circ}$. Data tersebut didapatkan melalui website NASA (http://mirador.gsfc.nasa.gov). Dari data tersebut didapatkan parameter untuk menghitung intensitas curah hujan yaitu curah hujan rata-rata tahunan $\left(M_{t}\right)$ dan probabilitas hujan $\left(P_{0}\right)$. Nilai $M_{t}$ dan $P_{0}$ dihitung untuk setiap grid data pada koordinat $8^{\circ}$ LU $-10^{\circ}$ LS dan $93^{\circ}$ BT $-140^{\circ}$ BT. Nilai $M_{t}$ diperoleh dengan menjumlahkan data setahun sedangkan nilai $P_{0}$ diperoleh menggunakan persamaan (Azlan dkk., 2013):

$$
P_{0}=\frac{N_{R}}{N_{T}}
$$

dimana $N_{R}$ adalah jumlah data yang ada hujan (rain pixel) dan $N_{T}$ adalah jumlah data keseluruhan (total pixel). Model ITU-R P.837-6 (Recommendation ITU-R P.837-6, 2013) yang umum digunakan dalam mengestimasi intensitas curah hujan kemudian disederhanakan menjadi:

$$
P(R)=P_{0} \exp \left(-1,09 R \frac{1+b R}{1+c R}\right)
$$

dengan

$$
\begin{gathered}
b=\frac{M_{t}}{21797 P_{0}}, \\
c=26,02 b
\end{gathered}
$$

dimana $P_{0}$ adalah probabilitas hujan rata-rata tahunan, $R$ adalah intensitas curah hujan (mm/jam) dan $M_{t}$ adalah curah hujan rata-rata tahunan (mm). 

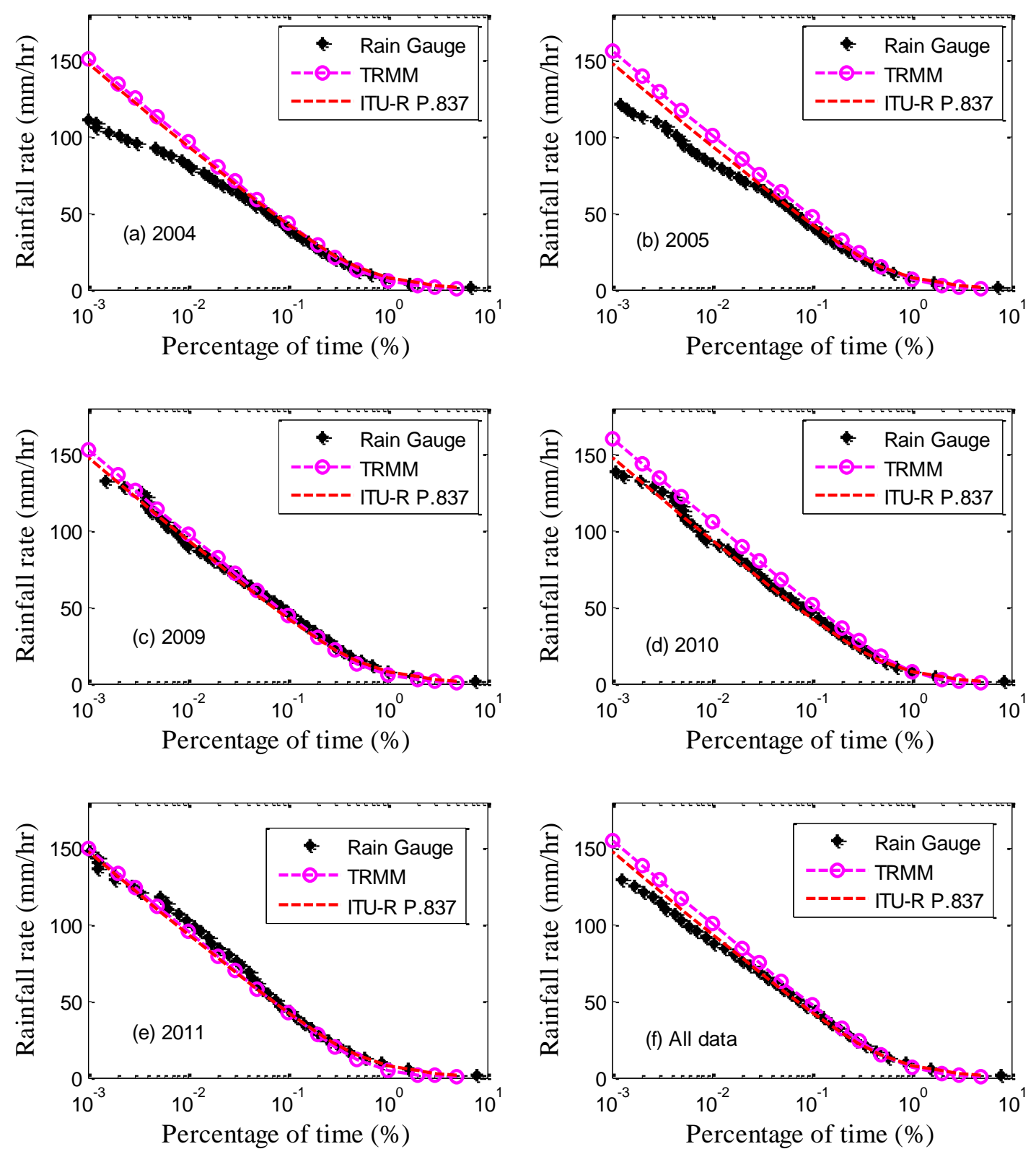

Gambar 1. Perbandingan intensitas curah hujan hasil model dengan data rain gauge di

Kototabang

Untuk validasi hasil model, penulis hanya memiliki data pengamatan di dua lokasi yaitu data rain gauge di Kototabang dan data DBSG3 di Bandung. Data DBSG3 adalah data pengukuran pada beberapa titik di dunia yang dimiliki ITU-R Study Group 3. DBSG3 digunakan oleh ITU-R untuk memvalidasi semua model yang dikembangkan. Untuk Indonesia, data DBSG3 hanya tersedia untuk kawasan Bandung. Akurasi model diuji menggunakan root-mean-square-error (RMSE)

$$
R M S E=\sqrt{\frac{\sum\left(x_{u}-x_{h}\right)^{2}}{n}},
$$


dan average percentage error (APE)

$$
A P E=\left(\frac{1}{n} \sum \frac{\left|x_{u}-x_{h}\right|}{x_{u}}\right) \times 100 \%
$$

dimana $x_{u}$ adalah nilai yang terukur oleh rain gauge atau DSBG3 dan $x_{h}$ adalah nilai yang dihitung oleh model baik dengan input dari TRMM maupun dengan input standar ITU-R.

\section{HASIL DAN DISKUSI}

\subsection{Estimasi Intensitas Curah Hujan di Kototabang}

$M_{t}$ dan $P_{0}$ yang didapatkan dari data TRMM digunakan untuk menghitung intensitas curah hujan dengan menggunakan Persamaan (2). Hasilnya kemudian dibandingkan dengan intensitas curah hujan dari model standar ITU-R P.837-6 dan data rain gauge di Kototabang (Gambar 1). Hasil yang ditampilkan pada Gambar 1 adalah untuk tahun dimana data rain gauge di Kototabang lengkap satu tahun pengamatan. Penjelasan tentang ketersediaan data di Kototabang dapat dilihat pada tulisan Marzuki dkk. (2016). Dari perbandingan ini didapatkan bahwa nilai intensitas curah hujan dari model ITU-R P.837-6 pada setiap tahun pengamatan memiliki nilai yang sama sedangkan hasil dari data TRMM 3A25 dan 3B43 memiliki nilai yang berbeda-beda. Hal ini menunjukkan bahwa ITU-R mengestimasi nilai intensitas curah hujan yang stasioner sepanjang tahunnya.

Tabel 1. RMSE dari Gambar 1 yang dihitung antara curah hujan hasil pemodelan dengan data rain gauge di Kototabang

\begin{tabular}{ccccccc}
\hline & \multicolumn{5}{c}{ Persentase waktu (Percentage of Time) } \\
\cline { 2 - 7 } Tahun & \multicolumn{2}{c}{ Semua } & \multicolumn{2}{c}{$<\mathbf{0 . 1 \%}$} & \multicolumn{2}{c}{$\geq \mathbf{0 . 1 \%}$} \\
\cline { 2 - 7 } & \multicolumn{2}{c}{ Input ITU-R } & \multicolumn{2}{c}{ Input ITU-R } & \multicolumn{2}{c}{ Input ITU-R } \\
\cline { 2 - 7 } & TRMM & ERA-40 & TRMM & ERA-40 & TRMM & ERA-40 \\
\hline 2004 & 22.82 & 20.70 & 27.25 & 24.71 & $\mathbf{1 . 9 2}$ & 1.95 \\
2005 & 22.42 & 16.95 & 26.30 & 19.96 & 4.02 & 0.98 \\
2009 & 15.81 & 13.62 & 18.57 & 15.95 & $\mathbf{2 . 6 1}$ & 2.82 \\
2010 & 12.77 & 5.75 & 14.85 & 6.66 & 3.85 & 2.04 \\
2011 & $\mathbf{5 . 7 2}$ & 6.66 & $\mathbf{6 . 4 4}$ & 7.63 & 2.29 & 0.64 \\
\hline Semua & 21.97 & 16.70 & 25.19 & 19.15 & 1.73 & 1.37 \\
\hline
\end{tabular}

Secara umum intensitas curah hujan dari data TRMM menyerupai model ITU-R untuk semua persentase waktu curah hujan. Kedua model mengestimasi curah hujan lebih tinggi dari data rain gauge terutama untuk persentase waktu $>0.01 \%$. Akurasi dari model bervariasi setiap tahun. Untuk tahun 2004, 2009 dan 2011 estimasi intensitas curah hujan dari data TRMM sangat mirip dengan model ITU-R untuk semua persentase waktu curah hujan. Di sisi lain, untuk tahun 2005, 2010 dan rata-rata data keseluruhan (Gambar 1f), TRMM mengestimasi lebih tinggi dari ITU-R standar. 
Tabel 2 Rata-rata persentase error dari Gambar 1 yang dihitung antara curah hujan hasil pemodelan dengan data rain gauge di Kototabang

\begin{tabular}{ccccccc}
\hline & \multicolumn{5}{c}{ Persentase waktu (Percentage of Time) } \\
\cline { 2 - 7 } Tahun & \multicolumn{2}{c}{ Semua } & \multicolumn{2}{c}{$<\mathbf{0 . 1 \%}$} & \multicolumn{2}{c}{$\geq \mathbf{0 . 1 \%}$} \\
\cline { 2 - 7 } & \multicolumn{2}{c}{ Input ITU-R } & \multicolumn{2}{c}{ Input ITU-R } & \multicolumn{2}{c}{ Input ITU-R } \\
\cline { 2 - 7 } & TRMM & ERA-40 & TRMM & ERA-40 & TRMM & ERA-40 \\
\hline 2004 & 19.58 & 16.99 & 22.26 & 19.07 & 13.33 & 12.13 \\
2005 & 21.00 & 11.72 & 21.65 & 13.40 & 19.32 & 7.40 \\
2009 & 12.65 & 8.58 & 9.08 & 7.70 & 21.82 & 10.86 \\
2010 & 15.21 & 5.47 & 12.79 & 4.15 & 21.43 & 8.87 \\
2011 & 9.26 & 5.86 & $\mathbf{4 . 8 7}$ & 5.76 & 23.16 & 6.17 \\
\hline Semua & 16.28 & 9.63 & 16.02 & 9.94 & 17.10 & 8.64 \\
\hline
\end{tabular}

Untuk memberikan gambaran kuantitatif dari model, maka dihitung nilai root mean square error (RMSE) dan rata-rata persentase error dari data intensitas curah hujan yang diplot pada Gambar 1 (Tabel 1 dan Tabel 2). Data rain gauge digunakan sebagai data acuan. Oktaviani (2018) memperlihatkan perbedaan akurasi model ITU-R untuk setiap persentase waktu. Oleh karena itu, pada Tabel 1 dan 2, dihitung juga RMSE dan persentase error untuk persentase waktu $<0.1 \%$ (hujan lebat) dan persentase waktu $>0.1 \%$ (hujan dengan intensitas ringan dan sedang). Untuk RMSE, TRMM memiliki nilai yang lebih kecil dari ITU-R untuk tahun 2004, 2009 dan 2011. Pada persentase waktu $>0.1 \%$ nilai RMSE relatif kecil karena intensitas curah hujan yang rendah. Untuk persentase error, ITU-R memiliki nilai yang lebih kecil dari yang didapatkan menggunakan satelit TRMM kecuali untuk tahun 2011 pada persentase waktu $<0.1 \%$. Hasil ini sedikit berbeda dengan yang didapatkan oleh Oktaviani (2018) dimana untuk persentase < $0.01 \%$ penggantian input ITU-R menggunakan Global Satellite Mapping of Precipitation (GSMaP) memberikan intensitas curah hujan yang lebih mendekati rain gauge dari yang didapatkan ITU-R dengan input standar. Namun, secara keseluruhan (untuk semua persentase waktu), akurasi model yang didapatkan dalam penelitian ini menggunakan TRMM 3A25 dan 3B43 lebih baik dari yang didapatkan Oktaviani (2018) yang ditandai dengan nilai RMSE yang lebih kecil.

\subsection{Estimasi Intensitas Curah Hujan di Bandung}

Gambar 2 memperlihatkan intensitas curah hujan di Bandung yang diestimasi menggunakan model dengan input dari data satelit TRMM dan dengan input standar. Data intensitas curah hujan dari DBSG3 digunakan sebagai pembanding dan data ini dianggap sebagai acuan karena merupakan hasil pengukuran. Karena data TRMM untuk tahun pengamatan DBSG3 tidak ada, maka digunakan nilai rata-rata $M_{t}$ dan $P_{0}$ dari semua data TRMM (data pada Gambar 1f). Hal ini bisa diterima karena ITU-R menggunakan asumsi iklim stasioner (stationary climate) di dalam pemodelan mereka sehingga intensitas curah hujan di suatu daerah tidak bergantung tahun. Dari Gambar 2 terlihat bahwa TRMM cukup akurat untuk tahun 1992 (Gambar 2a) dan untuk data pada Gambar 2e dimana tahun pengamatan dari data DBSG3 tidak disebutkan. Di sisi lain, ITU-R cukup akurat untuk tahun-tahun yang lain termasuk untuk rata-rata semua data (Gambar 2f). 
Untuk memberikan gambaran akurasi model secara kuantitatif, dihitung nilai RMSE (Tabel 3) dan rata-rata persentase error (Tabel 4). Sebagaimana yang terlihat dari Gambar 2, untuk keseluruhan persentase waktu, data TRMM memperlihatkan nilai RMSE dan persentase error yang kecil pada tahun 1992 dan data ke-5 (tahun tidak diketahui). Namun, untuk tahun dan data yang lain, RMSE dan persentase error ITU-R lebih kecil. Persentase error dari TRMM berkisar antara 9,52-58,72 \%. Persentase error dari ITU-R berkisar antara 10,63-34,82\%. Dengan demikian, batas bawah dari persentase error TRMM lebih kecil dari ITU-R.
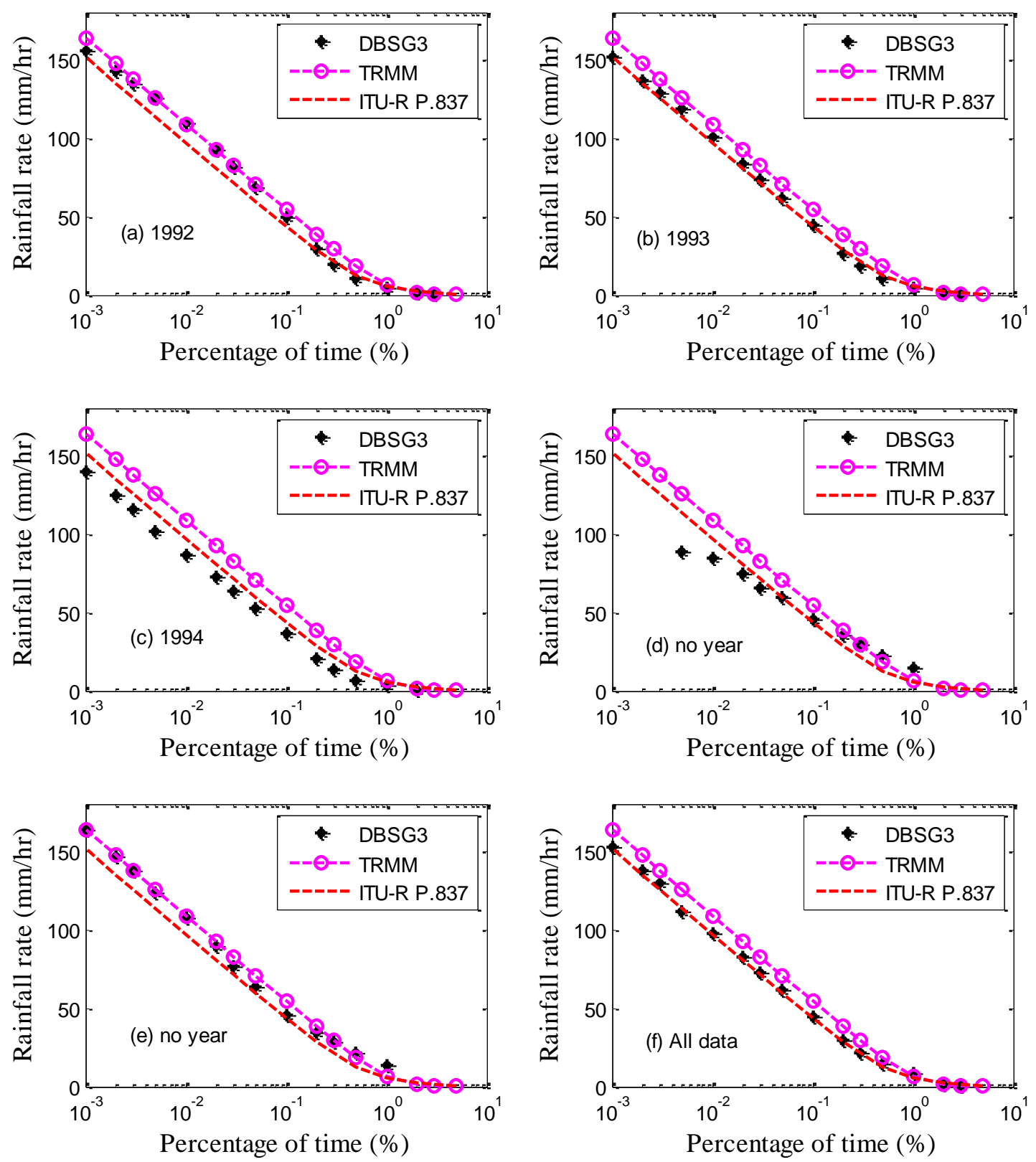

Gambar 2. Perbandingan estimasi intensitas curah hujan di Bandung (6.9 LS, 107.6 BT) dengan ITU-R dan TRMM, dibandingkan dengan data DBSG3. 
Akurasi dari model bergantung kepada persentase waktu dari intensitas curah hujan. Untuk persentase waktu $<0.1 \%$ (hujan lebat), RMSE dari TRMM berkisar antara 3,39$23,54 \mathrm{~mm} / \mathrm{h}$ dengan persentase error $1,89-28,43 \%$. Untuk persentase waktu yang sama, ITU-R memiliki RMSE antara 2,03-13,29 mm/h dengan persentase error 1,74-12,50\%. Untuk persentase waktu $>0.1 \%$ (hujan dengan intensitas ringan dan sedang), nilai RMSE kedua model cukup kecil yaitu 5,38-13,25 mm/h (ITU-R) dan 1,29-7.76 mm/h (ITU-R). Namun, persentase error dari kedua model cukup tinggi, secara umum di atas $20 \%$. Hal ini disebabkan oleh kecilnya nilai pembagi dari persamaan persentase error pada persentase waktu ini.

Tabel 3. RMSE dari Gambar 2 yang dihitung antara curah hujan hasil pemodelan dengan data DBSG3 di Bandung.

\begin{tabular}{ccccccc}
\hline & \multicolumn{3}{c}{ Persentase waktu (Percentage of Time) } \\
\cline { 2 - 7 } Tahun & \multicolumn{2}{c}{ Semua } & \multicolumn{2}{c}{$<\mathbf{0 . 1 \%}$} & \multicolumn{2}{c}{$\geq \mathbf{0 . 1 \%}$} \\
\cline { 2 - 7 } & \multicolumn{2}{c}{ Input ITU-R } & \multicolumn{2}{c}{ Input ITU-R } & \multicolumn{2}{c}{ Input ITU-R } \\
\cline { 2 - 7 } & TRMM & $\begin{array}{c}\text { ERA- } \\
\mathbf{4 0}\end{array}$ & TRMM & $\begin{array}{c}\text { ERA- } \\
\mathbf{4 0}\end{array}$ & TRMM & $\begin{array}{c}\text { ERA- } \\
\mathbf{4 0}\end{array}$ \\
\hline 1992 & $\mathbf{4 . 8 0}$ & $\mathbf{7 . 5 6}$ & $\mathbf{3 . 3 9}$ & $\mathbf{1 0 . 0 9}$ & 6.02 & 2.51 \\
1993 & 8.66 & 2.44 & 9.34 & 2.95 & 7.80 & 1.68 \\
1994 & 18.30 & 8.29 & 21.32 & 9.58 & 13.25 & 6.17 \\
- & 17.10 & 10.88 & 23.52 & 13.29 & 5.65 & 7.76 \\
- & $\mathbf{4 . 3 9}$ & $\mathbf{8 . 8 0}$ & $\mathbf{3 . 6 4}$ & $\mathbf{9 . 8 0}$ & $\mathbf{5 . 3 8}$ & $\mathbf{6 . 9 1}$ \\
\hline Semua & 8.72 & 1.72 & 10.54 & 2.03 & 6.00 & 1.29 \\
\hline
\end{tabular}

Tabel 4. Rata-rata persentase error dari Gambar 2 yang dihitung antara curah hujan hasil pemodelan dengan data DBSG3 di Bandung.

\begin{tabular}{ccccccc}
\hline & \multicolumn{4}{c}{ Persentase waktu (Percentage of Time) } \\
\cline { 2 - 7 } Tahun & \multicolumn{2}{c}{ Semua } & \multicolumn{2}{c}{$<\mathbf{0 . 1 \%}$} & \multicolumn{2}{c}{$\geq \mathbf{0 . 1 \%}$} \\
\cline { 2 - 7 } & \multicolumn{2}{c}{ Input ITU-R } & \multicolumn{2}{c}{ Input ITU-R } & \multicolumn{2}{c}{ Input ITU-R } \\
\cline { 2 - 7 } & TRMM & ERA-40 & TRMM & ERA-40 & TRMM & ERA-40 \\
\hline 1992 & 16.38 & 15.85 & $\mathbf{1 . 8 9}$ & $\mathbf{9 . 4 6}$ & 32.95 & 23.15 \\
1993 & 22.90 & 10.63 & 9.32 & 2.64 & 38.43 & 19.77 \\
1994 & 58.72 & 34.82 & 24.14 & 10.47 & 104.84 & 67.28 \\
- & 24.17 & 22.03 & 28.43 & 12.50 & $\mathbf{1 9 . 9 0}$ & $\mathbf{3 1 . 5 5}$ \\
- & $\mathbf{9 . 5 2}$ & $\mathbf{1 6 . 4 0}$ & $\mathbf{3 . 2 3}$ & $\mathbf{8 . 1 4}$ & $\mathbf{1 9 . 5 8}$ & $\mathbf{2 9 . 6 0}$ \\
\hline Semua & 16.18 & 11.13 & 10.79 & 1.74 & 22.35 & 21.86 \\
\hline
\end{tabular}

\section{KESIMPULAN}

Penggunaan data TRMM sebagai input model ITU-R P.837-6 cukup akurat untuk mengestimasi curah hujan di Indonesia. Walaupun demikian, akurasi model ITU-R dengan input data ERA-40 lebih baik daripada model ITU-R dengan input TRMM 3A25 dan 3B43. Hal ini terlihat dari nilai RMSE dan rata-rata persentase error ketika dibandingkan dengan data rain gauge di Kototabang dan data DBSG3 di Bandung. Hasil 
penelitian ini berbeda dengan yang didapatkan penelitian sebelumnya di Malaysia dimana model ITU-R dengan input TRMM 3A25 dan 3B43 lebih akurat daripada model ITU-R dengan input data ERA-40. Titik validasi yang digunakan dalam penelitian ini masih terbatas pada Kototabang dan Bandung, validasi untuk titik pengamatan yang lain sedang dilakukan dan akan diterbitkan pada artikel yang lain.

\section{UCAPAN TERIMAKASIH}

Penelitian ini didanai oleh PKM-PE tahun 2019. Selain itu, data dalam penelitian ini terutama data rain gauge di Kototabang tersedia dari Hibah Riset Dasar (Hibah KLN) Kemenristekdikti tahun 2019. Terimakasih kepada NASA yang telah menyediakan data TRMM 3A25 dan 3B43. Terimakasih juga kepada Universitas Shimane (Dr. Toyoshi Shimomai), Universitas Kyoto (Prof. Hiroyuki Hashiguchi) dan LAPAN yang telah mengoperasikan rain gauge di Kototabang.

\section{DAFTAR PUSTAKA}

Azlan, M. A. N., Luini, L., Din, J., \& Lam, H. Y. (2013). 1-Minute integrated rain rate statistics estimated from tropical rainfall measuring mission data. IEEE Antennas and Wireless Propagation Letters, 12, 132-135.

Capsoni, C. \& Luini, L. (2008). 1-Min rain rate statistics predictions from 1-hour rain rate statistics measurements. IEEE Transactions on Antennas and Propagation, 56 (3), $815-824$.

Maagt, P. J. T., Touw, S. I. E., Dijk, J., Brussaard G., \& Allnut, J. E. (1993). Propagation experiments in Indonesia. Electronics Letters, 29 (22).

Marzuki, Oktaviani, R., Meylani, L., Hashiguchi, H., Vonnisa, M., \& Harmadi. (2018) One-minute rain rate distribution in Indonesia derived from TRMM, GPM, and GSMAP data. Progress in Electromagnetics Research Symposium (PIERSToyama), 2134-2138.

Marzuki, Hashiguchi, H., Shimomai, T., \& Randeu, W. L. (2016). Cumulative distributions of rainfall rate over Sumatra. Progress in Electromagnetics Research $M, 49,1-8$.

Meylani, L. (2017). Pemanfaatan data satelit tropical rainfall measuring mission sebagai input model ITU-R untuk mengestimasi intensitas curah hujan di Indonesia (Skripsi). Universitas Andalas, Padang, Indonesia.

Oguchi, T., (1983). Electromagnetic wave propagation and scattering in rain and other hydrometeors, Proceedings of The IEEE, 71 (9), 1029-1078.

Oktaviani, R., \& Marzuki. (2019). Estimation of rainfall rate cumulative distribution in Indonesia using global satellite mapping of precipitation data. KnE Engineering, 259-265.

Recommendation ITU-R P.837-6. (2013). Radiowave propagation series, I.T.U., characteristics of precipitation for propagation modelling. International Telecommunications Union, Geneva: Author. 